\title{
EDITORIAL
}

\section{Emerging and re-emerging infectious diseases: a continuous challenge for Europe}

\author{
GianLuca Quaglio*, Jacques Demotes-Mainard" and Robert Loddenkemper
}

I $\mathrm{t}$ is estimated that infectious diseases represent roughly $10 \%$ of the total burden of disease in the European Union (EU) [1, 2]. This figure, however, might be underestimated because it does not fully take into account the whole spectrum of long-term sequelae caused by infections [3].

The growing problem of antibiotic resistance represents a major health burden for the EU. For example, carbapenems are the major last-line class of antibiotics to treat infections with multidrug-resistant (MDR) Gram-negative bacteria such as Klebsiella pneumoniae (a frequent cause of pneumonia and urinary tract infections in hospitals). $15-50 \%$ of K. pneumoniae from bloodstream infections are resistant to carbapenems in the EU [4]. Another example is Staphylococcus aureus, a bacterium that can cause a variety of infections (from minor skin infections to severe pneumonia). Its adaptation has led to an MDR pathogen, methicillin-resistant $S$. aureus (MRSA). MRSA is associated with severe invasive disease. Initially, MRSA was only a nosocomial pathogen, but in the last 20 yrs it has been identified in the community (community-associated (CA)MRSA) [5]. The incidence of CA-MRSA pneumonia is estimated at $0.51-0.64$ cases per 100,000 population. Since the incidence of community-acquired pneumonia (CAP) is between 100 and 1,000 per 100,000 population [6], the frequency of CA-MRSA pneumonia can be estimated to be between one in 200 and one in 2,000 cases of CAP [5]. CA-MRSA pneumonia is a severe disease with $75-85 \%$ of affected patients being admitted to the intensive care unit and 20-60\% dying [7].

Antibiotic resistance also represents a major problem from an economic perspective. In 2009, the European Centre for Diseases and Control (ECDC) and the European Medicines Agency estimated that each year 25,000 Europeans die as a direct consequence of an MDR infection. The economic impact was estimated at $€ 1.5$ billion per year. These figures were based on just five MDR bacteria, thus, it certainly is an underestimation [8].

The Science and Technology Option Assessment (STOA) Unit of the European Parliament and Aviesan (Alliance for Life Sciences and Health, grouping together the main stakeholders of the life and health sciences in France) organised a workshop

\footnotetext{
*Science and Technology Options Assessments (STOA), European Parliament, Brussels, Belgium. ${ }^{\#}$ ECRIN - INSERM, Paris, France. "German Central Committee against Tuberculosis (DZK), Berlin, Germany.
}

CORRESPONDENCE: G. Quaglio, Science and Technology Option Assessment, European Parliament, Rue Wiertz 60, B-1047 Brussels, Belgium. E-mail: gianluca.quaglio@europarl.europa.eu on emerging and re-emerging infectious diseases in Brussels, Belgium in June, 2012 [9]. The problem of emerging infectious diseases (EIDs) has recently captured the public imagination and the awareness of the scientific community and policy makers. Despite this attention, emerging infections are not a recent phenomenon and throughout history have always represented a major threat [10]. EIDs have been defined as those which have appeared in a population for the first time, or those which have existed but are spreading in prevalence or geographical range. For example, the recent epidemic of $Q$ fever in the Netherlands, the outbreak of Chikungunya fever in Italy, severe acute respiratory syndrome (SARS) caused by very virulent strains of new Coronaviruses, and aviary influenza, especially cases caused by the strain A/H1N1 [11-14].

Re-emerging diseases are known diseases that become a problem, again for a significant part of the population, after a previous decline in incidence: an important example is tuberculosis (TB).

In the World Health Organization (WHO) European Region, 418,000 (range 355,000-496,000) new TB cases were estimated in 2010 corresponding to an incidence of 47 cases per 100,000 population. More than 60,000 (range 40,000-90,000) deaths in the WHO Region were estimated as being due to TB, representing 6.7 cases per 100,000 population. TB notifications have been decreasing since 2005, indicating a lower incidence of TB. However, the prevalence of MDR-TB among new TB cases increased from $12 \%$ in 2009 to $13.7 \%$ in 2010 . Altogether, the WHO Region reported more than 29,000 MDR-TB patients, of whom $13.2 \%$ are estimated to be already extensively drugresistant (XDR-TB). In essence, despite a decrease in TB incidence, drug-resistant TB is becoming a major concern $[15,16]$.

"In the EU, as elsewhere, we face newly emerging threats: new influenza virus variants, new pathogenic microbes, especially those transmitted from animals, resurgent infections such as TB, resistance to antimicrobial drugs and the threat of bioterrorism. Europe is a potential 'hot spot' for emerging and re-emerging infectious diseases" said MEP Kent Johansson, a STOA Member.

It is becoming clearer that a mix of complex changes in European societies is increasingly creating new opportunities for infections to emerge, among them: 1) globalisation and environmental change (climate change, habitat destruction, migration, long distance travel, global trade, etc.); 2) demographic and social drivers (population ageing, social inequality and uncontrolled urbanisation); and 3) public health system drivers (antimicrobial resistance, health care capacity, animal 
health, etc.) [17]. Emergence can also be the consequence of microbial evolution and genetic changes in existing pathogens.

Over the last 6 yrs during the course of the Seventh Framework Programme, the European Commission has allocated more than $€ 543$ million to research and development into new drugs, vaccines and clinical investigations for infectious diseases. The results are striking. There are now more than 80 collaborative projects involving hundreds of research groups and, specifically for emerging infectious diseases, 29 projects are ongoing with a total budget of $€ 141$ million [18, 19].

\section{OVERARCHING CONCLUSIONS}

Throughout the meeting, three overarching aspects of EUsupported infectious diseases surfaced: 1) new tools to prevent and treat infections; 2 ) science (quality and thematic priorities); and 3) European research infrastructures.

In the EU, infectious disease surveillance is regulated by the European Parliament and the Council [20]. The ECDC was established in 2005, with the mission to monitor and prevent the spread of infectious diseases [21]. The current EU surveillance system is based on both annual country-level reporting and the detection of individual disease outbreaks through epidemic intelligence. Traditional surveillance is often insufficient for early detection of EIDs, which calls for the finetuning of current surveillance approaches [17]. Surveillance across the whole spectrum of human and animal diseases (risk analysis, integrated information systems, shared databases, and data and sample archives) should be supported by enhancing capacity and improved techniques. Acceptable guidelines for national and European real-time data communication and exchange should be developed. By concentrating on specific problems and/or selected strata of the population at risk (e.g. immunocompromised hosts), the ability to analyse new phenomena at a European level will be enhanced. While the technology for these challenges is available, the main obstacle that remains is the absence of an agreement on an improved data and information exchange system.

Concerning diagnostic and therapeutic approaches, the development of biotechnology has provided new opportunities. In this regard, the role of the Innovative Medicines Initiative (IMI) was emphasised. The IMI was set up to enhance the competitiveness of the pharmaceutical sector in Europe. It was launched in 2008 by the EU and the pharmaceutical industries, with a total budget of $€ 2$ billion, making the IMI the largest public-private partnership in life sciences research and development [22]. Safe and efficacious vaccines are required for both humans and animals: they are one of the single most cost-effective public health approaches and vaccine innovation is vital to reduce the incidence of antimicrobial resistance [23]. The problem of EIDs and the threat of bioterrorism highlight the need for more effective action in the field.

The science behind emerging and re-emerging infectious diseases remain largely unexplored but holds an extremely rich potential for innovation and discovery. The science in this field needs interdisciplinary research, principally in the fields of human and veterinary medicine, but also others (ecology, zoology, meteorology, etc.). The workshop participants shared the view that there is a need to go back to basic research, pointing out that there are huge gaps in our understanding of the biology, immunology and pathophysiology of many infectious diseases [23]. For example, basic research should be pursued to increase our knowledge of the viruses and their interaction with the host in order to develop both prophylactic and therapeutic tools. In addition, efforts to identify the natural reservoirs should continue.

Basic and applied scientists need to work together in an integrated approach [24]. Three areas of research in which more emphasis is necessary are: 1) an improved understanding of the host-pathogen relationship; 2) to clarify the factors and the mechanisms of transmission of pathogens and the role of vectors; and 3) to better understand the complete ecology of the disease (e.g. how pathogens interact with wildlife and/or the environment). Finally, how the different concepts and capacities of academic and industrial research on new emerging diseases can work together still remains a major challenge [25].

One of Europe's major assets for tackling emerging and reemerging infections and antimicrobial resistance lies in the recent development of pan-European research infrastructures in the life sciences sector. The European Strategy Forum on Research Infrastructures (ESFRI) roadmap established priorities for the construction and operation of research instruments, making cutting edge and high throughput technologies accessible for the scientific communities across Europe [26]. The ESFRI roadmap infrastructures in the biological and medical sciences are distributed infrastructures, taking advantage of the coordination of national capacities to reach the critical mass (resulting in a paradigm shift similar to that which occurred in physics during the 20th century). Among the ESFRI-biological and medical sciences infrastructures, some are particularly relevant to infectious diseases, such as: the infrastructure for translational research (EATRIS); the European infrastructure for phenotyping and archiving of model mammalian genomes (INFRAFRONTIER); the European Research Infrastructure on Highly Pathogenic Agents (ERINHA); Microbial Resource Research Infrastructure (MIRRI); and the European Clinical Research Infrastructures Network (ECRIN) [27-29].

\section{BETTER COLLABORATION BETWEEN POLICY MAKERS AND SCIENTISTS}

Based on the presentations and discussions during the meeting, several ideas emerged for a better collaboration between policy makers and the scientific community. In Europe, Member States are confronted with increasing demands for regulation; primarily from EU institutions, but also from regulatory agencies, legal and ethical expert groups, etc. [25]. Tackling this broader political challenge requires several actions: first to reassess the balance of responsibilities for public health between the Member States and the European institutions and, at the same time, increase public investment in health infrastructure and research [23]. In parallel, the scientific community also needs to do more, such as filling the current knowledge gaps while exploring new opportunities and methods to provide evidencebased inputs for policy makers [30].

"We too often tend to forget that a crucial role in the equation of emerging diseases is played by cultural, social and economic factors. Such components do not only affect the immediate spread of the disease, but they will continue to exert a strong influence in the long term. I acknowledge that much has 
already been achieved by the European Institutions and at Member State level. However, the public health problems are urgent and there is significant capacity to do more to improve health services and public health policy", said Antonio Correia de Campos, STOA Chairman.

During this period of economic weakness, it is necessary to establish new procedures to ensure a straight, direct interaction between health policy, applied research and basic science in order to identify the health priorities in EIDs. This process requires an intercultural and interdisciplinary collaboration at the international level [30]. "The EU must be more ambitious in capitalising on its scientific capabilities and leadership and in building new linkages between academia, industry, health services and politics", concluded Antonio Correia de Campos.

\section{STATEMENT OF INTEREST}

None declared.

\section{REFERENCES}

1 Lopez AD, Mathers CD, Ezzati M, et al. Global and regional burden of disease and risk factors, 2001: systematic analysis of population health data. Lancet 2006; 367: 1747-1757.

2 van Lier EA, Havelaar AH, Nanda A. The burden of infectious diseases in Europe: a pilot study. Euro Surveill 2007; 12: E3-E4.

3 Kretzschmar M, Mangen MJ, Pinheiro P, et al. New methodology for estimating the burden of infectious diseases in Europe. PLoS Med 2012; 9: e1001205.

4 European Centre for Disease Prevention and Control. Antimicrobial Resistance Surveillance in Europe. Annual report of the European Antimicrobial Resistance Surveillance Network (EARS-Net) 2010. Stockholm, ECDC, 2011.

5 Nakou A, Woodhead M, Torres A. MRSA as a cause of community-acquired pneumonia. Eur Respir J 2009; 34: 1013-1014.

6 Woodhead M. The European vision of community-acquired pneumonia. Semin Respir Crit Care Med 2009; 30: 136-145.

7 Vardakas KZ, Matthaiou DK, Falagas ME. Incidence, characteristics and outcomes of patients with severe community acquiredMRSA pneumonia. Eur Respir J 2009; 34: 1148-1158.

8 European Centre for Disease Prevention and Control, European Medicines Agency. The Bacterial Challenge: Time to React. A call to narrow the gap between multidrug-resistant bacteria in the EU and the development of new antibacterial agents 2009. Stockholm, ECDC, 2009.

9 European Parliament/Science and Technology Option Assessment (STOA). Emerging and re-emerging infectious disease: a continuing challenge for Europe. www.europarl.europa.eu/stoa/cms/ home/events/workshops/infectious_diseases Date last updated: June 30, 2012. Date last accessed: July 15, 2012.

10 Barrett R, Kuzawa CW, McDade T, et al. Emerging and reemerging infectious diseases: the third epidemiologic transition. Annu Rev Anthropol 1998; 27: 247-271.

11 Rezza G, Nicoletti L, Angelini R, et al. Infection with Chikungunya virus in Italy: an outbreak in a temperate region. Lancet 2007; 370: 1840-1846.

12 Van der Hoek W, Dijkstra F, Schimmer B, et al. Q fever in the Netherlands: an update on the epidemiology and control measures. Euro Surveill 2010; 15: 19520.
13 Pugliese A, Beltramo T, Torre D. Emerging and re-emerging viral infections in Europe. Cell Biochem Funct 2007; 25: 1-13.

14 Snell NJ. Novel and re-emerging respiratory infections. Expert Rev Anti Infect Ther 2004; 2: 405-412.

15 European Centre for Disease Prevention and Control/World Health Organization Regional Office for Europe. Tuberculosis surveillance and monitoring in Europe 2012.

16 Loddenkemper R, Sotgiu G, Mitnick CD. Cost of tuberculosis in the era of multidrug resistance: will it become unaffordable? Eur Respir J 2012; 40: 9-11.

17 Lindgren E, Andersson Y, Suk JE, et al. Public health. Monitoring EU emerging infectious disease risk due to climate change. Science 2012; 336: 418-419.

18 Lång H, Quaglio GL, Olesen OF. Tuberculosis research in the European Union: past achievements and future challenges. Tuberculosis 2010; 90: 1-6.

19 European Commission. Research and Innovation. Infectious diseases. http://ec.europa.eu/research/health/infectious-diseases/ index_en.html Date last updated: April 25, 2012. Date last accessed: July 15, 2012.

20 Decision No. 2119/98/EC of the European Parliament and of the Council of 24 September 1998 setting up a network for the epidemiological surveillance and control of communicable diseases in the Community. Official Journal of the European Communities. October 3, 1998. http:/ / eurlex.europa.eu/LexUriServ/LexUriServ. do?uri=OJ:L:1998:268:0001:0006:EN:PDF

21 European Centre for Disease Prevention and Control. Mission. www.ecdc.europa.eu/en/aboutus/Mission/Pages/Mission.aspx Date last updated: June 18, 2012. Date last accessed: July 15, 2012.

22 Goldman M. The innovative medicines initiative: a European response to the innovation challenge. Clinical Pharmacol Ther 2012; 91: 418-425.

23 Fears R, van der Meer JW, ter Meulen V. The changing burden of infectious disease in Europe. Sci Transl Med 2011; 3: $103 \mathrm{~cm} 30$.

24 Fears R, van der Meer JW, ter Meulen V. Translational medicine policy issues in infectious disease. Sci Transl Med 2010; 2: 14cm2.

25 Albani S, Prakken B. The advancement of translational medicine from regional challenges to global solutions. Nat Med 2009; 15: 1006-1009.

26 European Commission. ESFRI. Research Infrastructures. http:// ec.europa.eu/research/infrastructures/index_en.cfm?pg=esfri Date last updated: March 13, 2012. Date last accessed: July 15, 2012.

27 European Clinical Research Infrastructure Network. Activities. www.ecrin.org/index.php?id=141 Date last updated: June 10, 2012. Date last accessed: July 15, 2012.

28 European Research Infrastructure on Highly Pathogenic Agents. Concept. www.erinha.eu/concept/concept.html Date last updated: July 2, 2012. Date last accessed: July 15, 2012.

29 Demotes-Mainard J, Kubiak C. A European perspective - the European clinical research infrastructures network. Ann Oncol 2011; 22: vii44-vii49.

30 European Academies Science Advisory Council. European Public Health and Innovation Policy for Infectious Disease: the view from EASAC. April 2011. www.easac.eu/fileadmin/PDF_s/reports_ statements/EASAC\%20Infectious\%20Disease \%20report $\% 20 \mathrm{web} \%$ 20document.pdf 